\title{
The Analytical Applications And Biological Activity of Hydroxamic acids
}

\author{
M. J. A. Abualreish ${ }^{1,2^{\star}}$ and M. A. Abdein ${ }^{3,4^{* \star}}$
}

1. Department of Chemistry, Faculty of Science, Northern Boarder University, Arar, Kingdom of Saudi Arabia (current address).

2. Department of Chemistry, Faculty of Science and Technology, Omdurman Islamic University ,Sudan (permanent address).

3. Department of Biology, Division of Botany, Faculty of Science, Northern Boarder University, Arar, Kingdom of Saud Arabia (current address).

4. Vegetables Breeding Department, Horticulture Inst., ARC, Giza, Egypt (permanent address). *E-mail of the corresponding author: Mustjeed_2008@hotmail.com

${ }^{* *}$ E-mail of the second author: abdeingene@yahoo.com

\section{ABSTRACT}

Hydroxamic acids play a vital role in applied chemistry, the present literature review is an investigation on the analytical applications and biological activity of hydroxamic acids .

The review includes a survey of the historical background of hydroxamic acids, their general structure, classification, physical properties, stability and occurrence in nature .

In addition the review discuss the synthesis and identification of hydroxamic acids, in which different methods of synthesis and different analytical techniques for identification were outlined .

The review also includes the wide use of hydroxamic acids, mainly their analytical applications and a summarized account of the biological activity of hydroxamic acids.

\section{Keywords}

Hydroxamic acids ; Analytical applications; Biological activity

\section{Council for Innovative Research}

Peer Review Research Publishing System

\section{Journal: Journal of Advances in Chemistry}

\author{
Vol. 10, No. 1
}

\section{editorjaconline@gmail.com}




\section{INTRODUCTION}

The history of hydroxamic acids:

Hydroxamic acid have been known since 1869 with the discovery of oxalo hydroxamic acid by Lossen [1].

Dispite this, researches on these compounds were lacking until the 1980,after which an enormous amount of in formation has accumulated with respect to their bio medical applications, synthesis, determination of their metal complexes [2], their pharmaceutical [3] and industrial applications [4]so the chemistry of hydroxamic acid has received considerable attention [5], particularly important is their role as siderphores, as well as a model system for natural siderphores [6]. Siderphores are low molecular neeight multidentate ligands, which serve as Fe(III) - specific chelators secreted by micro-organisms to extract and internalize scarce ferric ions with high affinity and specificity from their enviroment.

\section{The general structure of hydroxamic acids :}

Hydroxamic acids are a class of chemical compounds sharing the same functional group in which a hydroxylamine is inserted into a carboxylic acid. It's general structure is R-CO-NH-OH [7].

\section{$\mathbf{R} \equiv$ an organic residue}

CO $\equiv$ a carbonyl group

$\mathrm{NH}-\mathrm{OH} \equiv$ a hydroxylamine<smiles>[R]C(=O)NO</smiles>

So hydroxamic acid may be regarded as derivative of both hydroxylamine and carboxylic acids.

Structurally, hydroxamic acids can be represented in their two tautomeric forms (II) and (III).<smiles>[R]C(=O)NO</smiles>

II

Ketoform

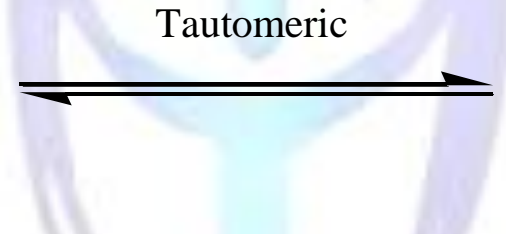

Enolform<smiles>[R]/C(O)=N/O</smiles>

III

Or by substitution of the hydrogen atom attached to the nitragen atom in (II) by alkyl or arylgroups

IV

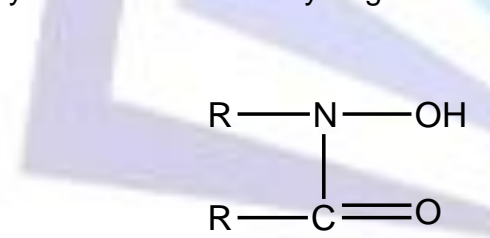

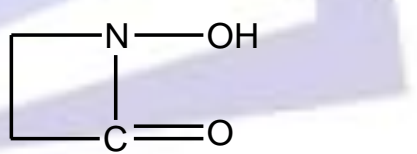

V

Numerous $\mathrm{N}$ - sudstituted hydroxamic acid of type (IV)can be obtained.

\section{classification of hydroxamic acids:}

Hydoxamic acids have been classified as primary as shown in structure(II) above or secondary as in (IV) or cyclic as in (V).

Mizukami and nagata [8] have replaced the oxygen atom by sulphur atom to get thio hydroxamic acid (VI) and(VII) below:<smiles>[R]C(=S)N([R])O</smiles>

VI

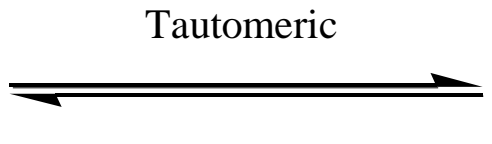




\section{physical properties of hydroxamic acids:}

Generally,hydroxamic acids are white solids, they are soluble in chloroform carbon tetrachloride and some other organic solvents, but sparingly soluble in water. They are weakly acidic compounds [9] which form metal complexes by chelation of metal ion between the two oxygen atoms of the monoanion to give a five membered ring.<smiles>[R]C(=O)NO</smiles><smiles></smiles>

Agrawal and tandon [10] ,have determined the ionization conslants (pKa) of ten $\mathrm{N}$-aryl hydroxamic acids in aqueous media,they found that at $25 \mathrm{C}^{\circ}$ the pka values are in the range of $8.08-8.59$,where at $35 \mathrm{C}^{\circ}$ the pka values range from 8.01- 8.56. Hydroxamic acids are stronger than phenol (pka=9.89), since they are differ widely in their structer and basicity. The acidity of hydroxamic acids may be attributed mainly to the - $\mathrm{OH}$ group and it's supression to intra molecular hydrogen bonding [11].Cyclic hydroxamic acids [12] in the solid state , ,are capable of intramolecular(V III)
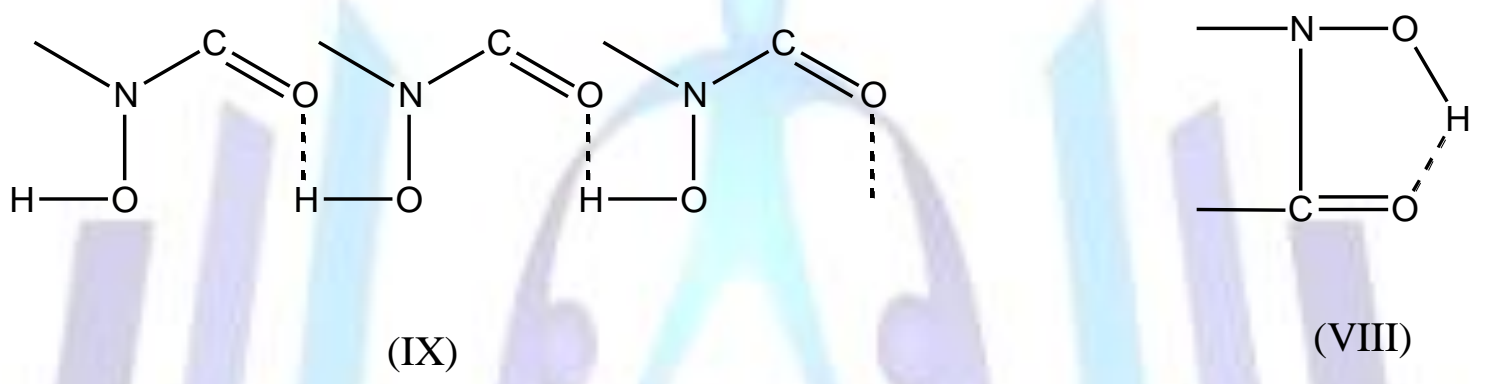

and intermolecular(IX) hydrogen-bonding involving the N-hydroxyl and carbonyl groups. Couts and Elizabeth[12] have observed that the position and intensity of the carbonyl and the hydroxyl infra red absorption bonds vary considerably from one hydroxamic acid to another,they found that an intramolecularly hydrogen-bonded carbonyl group absorbs infrared radiation at a lower frequency than the corresponding intermolecularly hydrogen bonded carbonyl group,in addition when hydrogen bonding is intramolecular, the $-\mathrm{OH}$ stretching band is usually broad, where as a sharp hydroxyl absorption band is generally obtained when hydrogen bonding is intermolecular.

\section{Stability of hydroxamic acids:}

The properties of hydroxamic acids strongly depend on the mode of ionization. N-unsubstituted hydroxamic acids have two protons that can be ionized to form hydroxamate ions. The stability of hydroxamate ions has beed the topic of many recent scientific investigstions, as it is fundamental to the understanding of their properties.

Experimental and theoretical studies in gas phase suggest that hydroxamic acids ionize via $\mathrm{N}-\mathrm{H}$ bond dissouation,but experimental evidence [13] shows that hydroxamic acids ionize via O-H bond dissociation in solution which is supported by a molecular dynamics simulation.

\section{Hydroxamic acids in nature:}

The hydroxamic acid bond occurs in products from fungi,yeast,bacteria and plants. The -CO N(OH) bond arises by oxidation of a free or bound amino group in aunit structure which is ofter closely related to conventional amino acids

[14].

Ferrichrome was the first siderphore to be isolated and characterized from the fungi Ustilago.sphaerogena in 1952 [15] . The chemistry of ferrichrome type compounds, which are ferric tri hydroxamate containing peptides, has been worked out in detail and includes a complete crystallographic analysis of the ferrichrome A.molecule [14].

Coprogen is a linear tri hydroxamate produced by penicillium specis and Neurospora. crassa and was first isolated and characterized by Hesseltine and coworkers[16].

Fusarinines $A$ and $B$ are two naturally occuring hydroxamic acids prouced by fusarium. roseum have been isolated and their structures were determined [17]. Several hydroxamic acids in addition fusarinine are found in the culture fluid of fusaria,these compounds represent a new class of naturally occusing hydroxamic acids in which the hydroxamate subunits are joined by ester linkage rather than the usual peptide bonds ,the compounds are amorphous, hydroscopic and yellow or ligth brown. 


\section{MATERIAL AND METHODS}

\subsection{Synthesis of hydroxamic acids:}

Several methods for the synthesis of hydroxamic acids have been described, the following is the summary of the famous and widely used methods:

\subsubsection{The coupling of $\mathrm{N}$-aryl or alkyl hydroxyl amine with acid chloride [18].}

The coupling of $\mathrm{N}$-aryl or alkyl hydroxyl amine with acid chloride in basic medium at $\mathrm{O}^{\circ} \mathrm{C}$ gives corresponding $\mathrm{N}$ phenylbenzo hydroxamic acids.

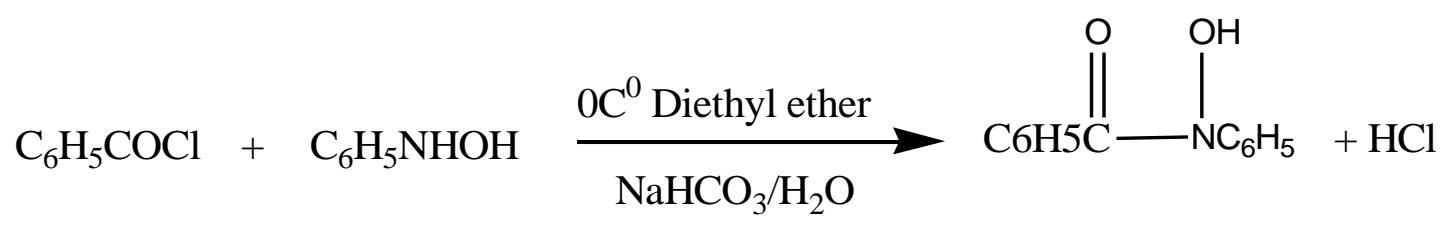

\subsection{2 . Reactions of carbonyl group with nitroso compounds:}

\subsection{1 Reaction of formaldehyde with substituted nitroso benzenes[19]:}

Formaldehyde reacts with substituted nitroso benzenes giving the corresponding $\mathrm{N}$-phenyl hydroxamic acids.<smiles>C=O</smiles>

$$
+\mathrm{C}_{6} \mathrm{H}_{5} \mathrm{NO}
$$<smiles>O=CN(O)c1ccccc1</smiles>

\subsubsection{Reaction of pyruvic acid or acetaldehyde with substituted nitroso benzenes[20] :}

Pyruvic acid and acetaldehyde react with substituted nitrosobenzenes to give the corresponding $\mathrm{N}$-phenyl acetohydroxamic acids. A mechanism for these reactions involving three sequential steps is proposed.

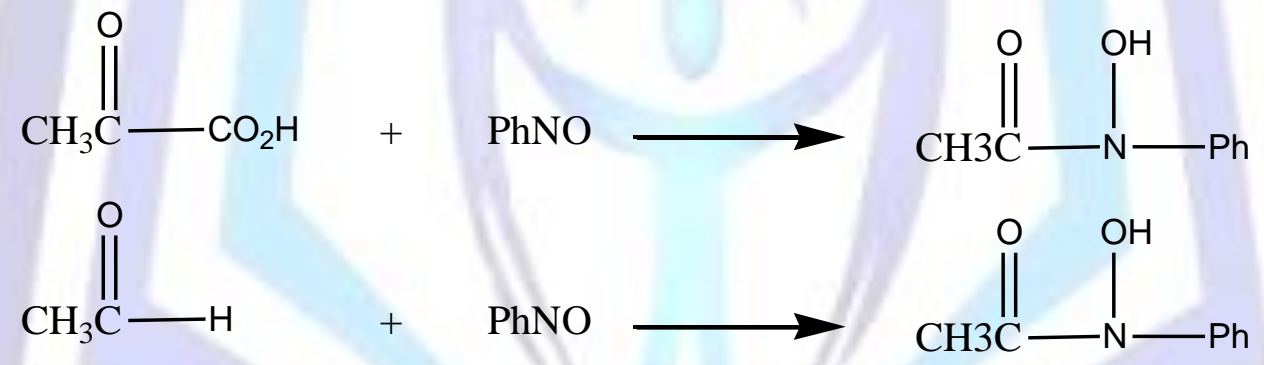

\subsubsection{Deprotection of O-benzyl hydroxamates [21]:}

$\mathbf{P d} / \mathrm{BasO}_{4}$ was found to be an efficient catalyst in the deprotection of O-benzyl hydroxamates via hydrogenation to give the corresponding hydroxamic acid.<smiles>[R]C(=O)NOCc1ccccc1</smiles>

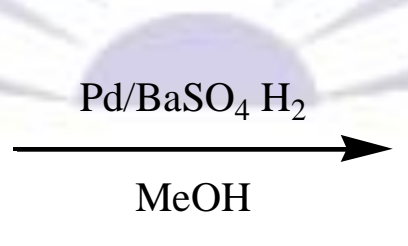<smiles>[R]C(=O)NO</smiles>

\subsubsection{Hydroxyamination of esters [21]:}

The direct solution phase hydroxyamination of esters in present of small amount of ICCN as catalyst leads to the formation of hydroxamic acid.<smiles>[R]C(=O)OC</smiles>

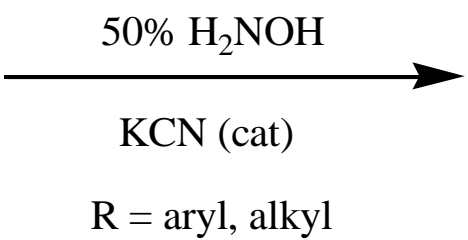<smiles>[R]C(=O)NO</smiles> 


\subsection{5 . Reaction of 2-Nitro so-2-Methyl propane with formaldehyde , glyoxylate and Glyoxylic acid [22]:}

2-nitroso-2-methyl propane reacts with formaldehyde,glyoxylate and glyoxylic acid giving the corresponding $\mathrm{N}$-t- butyl hydroxamic acid.

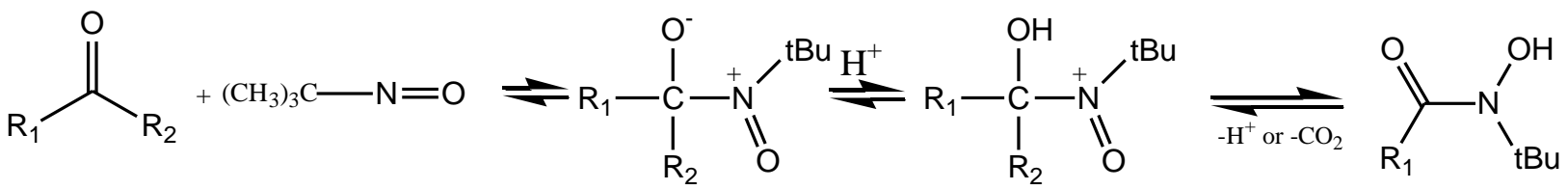

\subsubsection{The Angeli -Rimini reaction[23] [24]:}

This is a reaction between and aldehyde and the sulfonamide $\mathrm{N}$-hydroxy benzene sulfonamide in presence of base forming a hydroxamic acid.

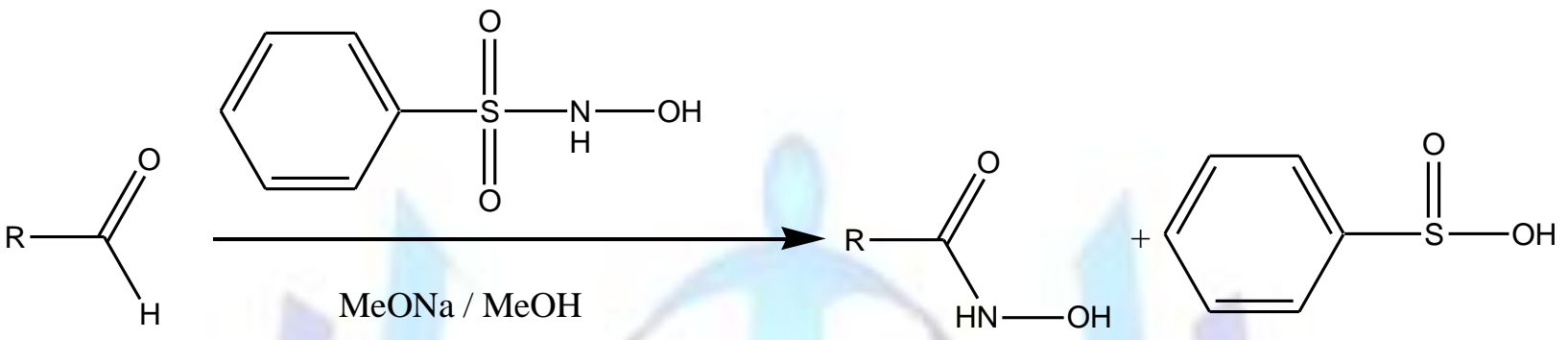

\subsection{Identification of hydroxamic acids:}

After the synthesis of ahydroxamic acid by any of the methods out lined above, it can be identified by the following.

a. It’s melting point

b. Infra-red spectroscopy(IR):

The infra-red spectra of hydroxamic acids[11]show characteristic bands associated with the hydroxamic acid functional grouping due to $(\mathrm{OH}),(\mathrm{C}=\mathrm{O})$ and $(\mathrm{N}-\mathrm{O})$ stretching vibration. These frequencies are generally assigned in the region of $3200 \mathrm{~cm}^{-1}, 1600 \mathrm{~cm}^{-1}$ and $910 \mathrm{~cm}^{-1}$, respectively .

c. Characteristic color reaction:

Hydroxamic acids in chloroform with a solution of ferric chloride in acidic medium give red-blood colour in the chloroform layer.

Also hydroxamic acids in chloroform with a solution of vanadium (V) in acidic medium give deep violet color in the chloroform layer characteristic of hydroxamic acid.

d. Elemental analysis : Determination of the nitrogen content[25].

e. Nuclear magnetic resonance spectroscopy (NMR):

There are a large number of structural parameters for NMR of different nuclei and many examples of how they can be applied to the analysis of hydroxamic acids.

Hydroxamic acids are made up of hydrogen ,carbon, nitrogen and oxygen nuclei ((some of their derivatives may also contain, fluorine, phosphorus and silicon)) . Thus spectra from hydrogen ,deuterium, tritium as well as carbon-13, nitrogen14 and nitrogen-15, oxygen-17 and other nuclei may be observed.

\subsection{Analytical applications of hydroxamic acids:}

\section{Introduction :}

The ability of hydroxamic acids to form stable transition metal complexes is the basis of their use fullness as an analytical regent ,this is the reason why hydroxamic acids have been used as chelating agents for determination of metals in samples of environmental and industrial importance[9]. The colored and stable solutions of these metal complexes often provide spectrophotometric methods for determination of several metal ions .

Hydroxamic acids having the bidentate functional grouping fulfill the basic requirements of complex formation with metal ions and s therefore form an important family of chelating agents .

The complex formation usually takes place with the replacement of the hydroxylamine hydrogen by the metal ion and ring closure through the carbon oxygen as shown below : 
<smiles>[R]C(=O)NO</smiles><smiles>[Y17][NH2+]C=C1CCC1</smiles><smiles></smiles>

All the metallic complexes of hydroxamic acids in which the $\mathrm{N}$ - hydrogen atom $(\mathrm{N}-\mathrm{H})$ is not replaced by any alkyl or aryl group are soluble in alkali showing acidic character of $\mathrm{N}$-hydrogen atom [26].

A summarized account of the preparation and properties of the hydroxamic acids complexes of the commonly used metals is given below [26]:

\section{Vanadium (V):}

Vanadium (V) reacts with certain hydroxamic acids, specially with those having another functional group attached to the side chain yielding a red to brown color in neutral medium. The complex formed has the compositon, vanadium : hydroxamic acids as 1:3. With aromatic hydroxamic acids vanadium gives a sparingly soluble dark - violet precipitate .

Iron (III):

The reaction of hydroxamic acids with ferric ion develops a red - violet coloration in acids medium with increasing $\mathrm{pH}$ this color changes slowly to wine-red and finally to orange - yellow. The composition of these colored complexes formed at different $\mathrm{pH}$ was found as follows :

\begin{tabular}{|c|c|c|}
\hline pH & $\begin{array}{c}\text { Composition } \\
\text { Fe }: \text { hydroxamic acid }\end{array}$ & $\begin{array}{c}\text { The color of the } \\
\text { complex }\end{array}$ \\
\hline Below 2 & $1: 1$ & Red -violet \\
\hline Between 2-3 & $1: 2$ & Wine - red \\
\hline Above 3 & $1: 3$ & Orange -yellow \\
\hline
\end{tabular}

\section{Cobalt (II):}

Cobalt(II) reacts with un substituted hydroxamic acids yielding a light pink color complex in acidic medium. The complex formed has the composition, cobalt(II): hydroxamic acid as 1:2 like the corresponding nickel compounds.

\section{Copper (II):}

Copper(II) gives with hydroxamic acids having no additional functional groups two different classes of compounds viz, a bright green color complex with the composition $1 \mathrm{Cu}: 1$ acid at $\mathrm{pH}=3$ and bluish green compound with the composition $1 \mathrm{Cu}: 2$ acid at $\mathrm{pH}=5$

Hydroxamic acids have also been used for the solid phase extraction of trace metals and as a ligand [9] has been incorporated into nifon film electrodes. Hydroxamic acids are used extensively in floatation of rare earth minerals during the concentration and extraction of ores to be subjected to further processing [7].

Hydroxamic also find applications as functionalizing agents for carbon nano tubes and polymer bound chelating agents [13].Hydroxamic acids also used in the formation of chelating ion exchange resin that gives the best sorption characteristics towards metal ions[27]. All hydroxamic acids in acids solutions, react with ferric chloride to give rust brown complex salts .<smiles>[R]C(=O)NO</smiles><smiles>c1ccccc1</smiles><smiles>IC1CCCCC1</smiles>

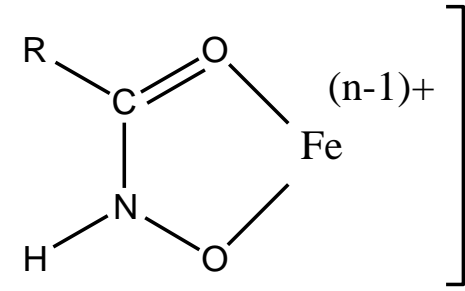
$+\mathrm{H}$

These colored complexes form the basis for the sensitive qualitative and quantitative determination of carboxylic acids and their derivatives too [21].

A few hydroxamic acids have been found to serve as suitable indicators e-g complexometric titration of ferric ion with EDTA[26]. 
Hydroxamic acids having a phenyl group attached to the side chain have been found to be most useful reagents for gravimetric estimation of metals copper 'cobalt, nickel, manganese(II), titanium(IV), iron( III), vanadium(V) etc [26]. Using paper impregnated with a solution of $\mathrm{N}$ - phenyl - benzohydroxamic acid in 2-octanonc a number of selective separations by paper chromatographic technique can be achieved [28].

$\mathrm{N}$-phenyl benzohydroxamic acids have been used in polarographic determination of tin and antimony [29].

\subsection{Biological activity of hydroxamic acids}

\section{Introduction :}

In the past most metabolic reactions on exogenous materials were considered to be detoxification reactions. However, during investigations on adverse effects of aromatic amines and related materials, it was discovered in the last 15 years that certain of these chemicals have pronounced effects on the hematopoietic system, that have pharmacological or pathological properties because of a novel toxication reaction. This reaction consists in substituting one hydrogen on the amine nitrogen with a hydroxyl group, i.e. N-hydroxylation([30].

Hydroxamic acids demonstrated mutagenic and antibacterial activities. These activities appear to be dependent on the hydroxamic acid function and are probably due to the interaction with deoxyribonucleic acid[21].

Hydroxamates are essential growth factors, or vitamins, for some microbes. They function as iron binding compounds, ((siderphores)) that solubilise iron and transport it into the cell. Iron is a key component of cytochromes and iron-sulphur proteins ((involved in electron transport)) and is thus important in cellular respiration[7] .

Salicylhydroxamic acid (SHAM) is a drug that is a potent and irreversible inhibitor of bacterial and plant urease usually used for urinary tract infections. It is also trypanocidal agent, when administered orally, it is metabolized to salicyamide which exerts analgesic, antipyretic and anti-inflammatory effects[31].

In plants, some fungi and some protists with the alternative oxidase (AOX) enzyme in the mitochondrial electro transport chain system, salicylhydroxamic acid acts as an inhibitor of the enzyme, blocking largely uninhibited flow of electrons through AOX[32], when AOX is blocked by SHAM, electrons are forced through the cytochrome pathway and through cytochrome iv, allowing observation of the operation of the cytochrome pathway without AOX activity.

A cetohydroxamic acid $(\mathrm{AHA})$ is a drug that is a potent and irreversible inhibitor of bacterial and plant urease usually used for urinary tract infections[7].

Natural hydroxamic acids and related compounds derived from 1,4-benoxazin-3-one structures inhibited the growth of the alga. Chlorella xanthell and the fungus Candida albicans[33], on the basis of structure- activity relationships the lipophilic character of the substituent in the aromatic ring and the electrophilic character of the hydroxamic function are suggested to be responsible for antialgal and anti- fungal activity, respectively.

Hydroxamic acids of the type 4-hydroxy-1,4- benzoxazin -3-ones constitute one of the most extensively studied secondary metabolites in relation to host plant resistance to pests and diseases. They play a major role in the defence of cereals against insects, fungi and bacteria[34].

A variety of hydroxamic acid derivatives have recently been touted for their potential use as inhibitors of hypertension, tumor growth, inflammation infection agents, asthma, arthritis, and more that hydroxamic acid derivatives have been examined as inhibitors of zinc metalloproteases, matrix metalloproteinases, leukotriene A4, hydrolases, ureases, lipoxigenases, cyclooxygenases, as well as peptide deformilases [35] .

Lipoxygenase plays an essential role in the biosynthesis of leukotrienes. leukotrienes have been implicated as mediators in the pathophysiology of inflammatory diseases. Simple stable molecules containing the hydroxamic acid functionality have been shown to inhibit 5-Lipoxygenase that block the biosynthesis of leukotriene in vivo [36].

Pulmonary fibrosis represents a fatal stage of interstitial lung diseases. histone deacetylases inhibitor suberoylanilide hydroxamic acid has antifibrotic and anti-inflammatory potential and approved as anti cancer drug[37].

\section{CONCLUSTION:}

The great attention received for the chemistry of hydroxamic acids is on the other hand, closely connected with the variety of their pharmaceutical, industrial and analytical applications. The ability of hydroxamic acids to form stable transitions metal complexes is the basis of their usefulness as analytical reagent for the sensitive qualitative and quantitative determinations. In addition to the trace elements $\mathrm{Mn}$, $\mathrm{Fe}, \mathrm{Co}, \mathrm{V}$ and $\mathrm{Cr}$, that are required for many forms of life, there are other elements such as nickel whose biological role is not yet clear. It is well known that reactions involving $\mathrm{C}=\mathrm{O}$ group present a large fraction of chemical and even larger fraction of biological reactions, and since hydroxamic acids are readily associated with both carboxylic acids and hydroxylamine, both structurally and synthetically, they have been very popular reagents and a large number of methods for the synthesis have been reported and the research will continue for anew synthetic methods. 


\section{REFERENCES}

[1] Rappoport .Z and Liebman.J.F "The chemistry of hydroxylamines ,oximes and hydroxamic acids " John Wiley and sons Itd,2009, part 1,187

[2] Mamion.C.J, Griffith.D and Nolan .K.B Eur.J.Inorg.Chem. $2004,3003$.

[3] Musser. J.H , Kreft A.F. , Bender R.H.W. (1990) J.Med.Chem.33,240.

[4] Odake- Sh., Okayama T. and Obata M. (1991) Chem.Pham.Bull .39,1489.

[5] Miller M.J. (1989) Chem.Rev.89,1536.

[6] Matzanke B.F., Mueller G. and Raymond K.N.)"Siderophore medicated Iron Transport ; Chemistry , Biology and Physical Properties in Physical Bioinorganic Chemistry " (1989) VCH Publishers New York.

[7] http:// en.wikipedia.org / wiki / hydroxamic acid.

[8] Meukami S.and Nagata K. (1968) Coordination.Chem.Rev.3(2),267.

[9] Rasuljan M. , Jan N. and Khwaja M.A. (1996) J.Chem.Soc.Pak.18(2),101.

[10] Agrawal Y.K.and Tandon S.G. (1973) "Electoanalytical chemistry and interfacial electrochemistry"43,158.

[11] Agrawal Y.K. (1970) Rev.Anal.Chem.5,3.

[12] Couts R.T. and Hindmarch K.W. (1968) Can.J. Pharm.Sci. 3(2),49.

[13] Senthilnithy R., Wearasinghe S. and Dissanayake D.P. (2008) J.Molecular.Structure.851(3),109 -114.

[14] Neilands J.B. (1967) Science 156(3781),1443-1447.

[15] Neilands J.B. (1952) J.Amer.Chem.Soc 74,4846.

[16] Hesseltine C.W. and.Pidacks .C (1952) J.Amer.Chem.Soc 74,1362.

[17] Sayer J.M.and Emery T.F. (1968) Biochemistry,7(1) ,184-190.

[18] Usha P.and Tandon S.G. (1967) J.of Chem.and Eng.Data , 12(1) ,143.

[19] Ursic S. (1993) Helv.Chimica.Acta.76,131.

[20] Ursic S. , Pilepic V., Vrcek V. (1993) J.Chem.Soc.Perkin.Trans.2,509.

[21] Nikam S.S., Komberg B.E. and Johnson D.R. (1995) Tetrahedron Letters,36(2),197-200.

[22] Rappoport Z.and Liebman J.F. (2009)"The chemistry of hydroxylamines ,oximes and hydroxamic acids " part 1,193.John Wiley and sons Itd.

[23] Viktor P. and Stanko U. (1994), Tetrahedron Letters, 35(40),7425-74287.

[24] Angeli . A. (1896), Gazz.Chim.Ital,26,17.

[25] Rimini . E. (1901), Gazz.Chim.Ital,31,84.

[26] A/mageed M.J., (1995) M.SC. Thesis, University of Khartoum .Sudan.

[27] Lajunen L.H. and Saarinen J. (1997) , Finn.Chem. Letters, 6,186.

[28] Mendez R., Snasankara V.N. (1990) Talanta, 37(6),591-594.

[29] Shendikar A.D., (1969) Talanta, 16(1),56.

[30] Weisburger J.H. and Weisburger E.K. (1973) Pharm.Rev. 35(1),1-6.

[31] Fishbein .W. and Carbone. P. (1965), J.Bio.Chem., 240,2407-2414.

[32] MorphyA.D. and Unnasch .N.L. (1999) Amer.Soc.For Micro.,43(3),651-654.

[33] Bravo H.R. and Lazo W. (1996) J.Agric.Food.Chem. 44(6),1569-1571.

[34] Hermann. M.N. (1988) Phytochemistry. 27(11),3349-3358.

[35] Muri E.M.and Weito .M.J. (2002) Current.Med.Chem. 9(17),1631-1653.

[36] Pontiki . E.and Litina. D. (2006) Medicinal Chemistry, 2(3),251-264.

[37] Wang. Z., Chen. C. and Finger. N. (2009) Eur.Respir.J., 34(1),145-155. 